\title{
ASSESSING THE INNOVATIVE PERFORMANCE OF ITALIAN SMEs
}

\author{
GIOVANNI MARSEGUERRA (*), DANIELA BRAGOLI (**), \\ FLAVIA CORTELEZZI $(* * *)$
}

Nota presentata dal s.c. Giovanni Marseguerra

(Adunanza del 3 novembre 2016)

SUNTO. - L'articolo si propone di valutare la performance innovativa delle PMI italiane attraverso l'analisi delle diverse dimensioni che concorrono a definire la capacità di innovazione delle imprese. Lo Scoreboard dell'Unione Europea (EIS) classifica l'Italia come un innovatore moderato. Tuttavia, disaggregando i dati, è possibile notare per l'Italia valori sotto la media europea relativamente ai fattori innovativi abilitanti (risorse umane, spesa in R\&S e supporto finanziario) e alle attività innovative delle imprese, ma valori superiori rispetto agli effetti economici dell'innovazione in termini di fatturato ed esportazioni. Sembrerebbe quindi che le PMI italiane siano state capaci di sfruttare le economie di agglomerazione, grazie alla proficua attività dei distretti industriali, divenendo gli attori di una storia di successo che combina crescita e innovazione. L'articolo infine identifica ed esamina brevemente tre questioni: l'impatto della struttura di capitale sull'innovazione, il ruolo della finanza pubblica nella scelta delle strategie di R\&S e il beneficio potenziale della cooperazione tra imprese e università.

(*) Istituto Lombardo, Accademia di Scienze e Lettere, Milan and Department of Mathematics for Economic, Financial and Actuarial Sciences, Catholic University of Milan, Italy. E-mail: giovanni.marseguerra@unicatt.it

(**) Department of Mathematics for Economic, Financial and Actuarial Sciences, Catholic University of Milan, Italy. E-mail: daniela.bragoli@unicatt.it

(*m*) Department of Law, Economics and Culture, Insubria University, Como, Italy. E-mail: flavia.cortelezzi@uninsubria.it 
ABSTRACT. - This article aims at assessing the innovative performance of Italian SMEs through the analysis of the many dimensions which together define firms' innovative capability. The European Innovation Scoreboard (EIS) classifies Italy as a moderate innovator. However, when disaggregating the data, it is possible to observe that Italy performs below the European average, when considering Innovation Enablers (e.g. Human Resources, R\&D and Financial Support) and Firms' Innovation Activities, and above the European average, when focusing on the the Output of innovation, i.e. its economic effect on exports and sales. Thus, it seems that Italian SMEs have been able to exploit agglomeration economies, due to the fruitful activity of industrial districts, and have been the actors of a success story, which combines growth and innovation. Finally, the article identifies and briefly examines three key questions: the impact of capital structure on innovation, the role of public funding in addressing $R \& D$ strategies and the potential benefit of the cooperation between firms and universities.

\section{INTRODUCTION}

From a macroeconomic perspective, investments are important to maintain and augment the production capacity of a country and enhance its international competitiveness. The regular renewal of machinery and equipment, buildings and infrastructure, as well as lifelong training of the workforce are necessary to build up and sustain the physical and human capital stock of an economy. Particularly important is investment in innovation activities. This type of investment fosters technological change and leads to improved resource efficiency, which in turn increases labor productivity and income per capita. In industrialized countries innovation is the key driver of sustainable economic growth and the crucial element to achieve higher welfare and create better living conditions in the long run. While being important from an aggregate point of view, innovation is also a crucial determinant of economic success at the firm level. Companies, which continuously invest in the development of new products and in the modernization of their production processes, can gain a competitive advantage over their rivals and increase their market share. Innovating enterprises grow significantly faster, both in terms of employment and turnover, and they are more profitable than non-innovating ones. Firms which invest and innovate too little tend to suffer a gradual decline in their productivity and risk losing their market position.

European SMEs ${ }^{1}$ are crucial in this respect as the "SME engine"

1 At present, SMEs have become the link between macroeconomics and 
is a central driver of investment and innovation. As clearly indicated in the Small Business Act for Europe, in a global changing environment, characterized by continuous structural change and enhanced competitive pressure, the role of SMEs has become even more important as providers of employment opportunities and as key players for the development and wellbeing of local and regional communities. The advantages of SMEs are based on their own characteristics, i.e. small scale, flexibility, speed of adaptation to the market needs, and the growing potential of entrepreneurship, innovation and international expansion. However, as it is well known, while these smaller businesses have many economic advantages, they also possess a number of organizational and market difficulties in their trading activities.

In sum, despite macroeconomic challenges, such as weak domestic demand, difficult access to finance and economic uncertainty, SMEs continue to be an essential part of the productive sector. Economic policy must therefore work against market failures that disproportionately affect SMEs and it must eliminate barriers to growth, in order to spur the sector's dynamism in terms of innovation and investment. In recent years, many public policies, which have been implemented in the EU and various European countries, acknowledge this and represent important steps in the right direction. ${ }^{2}$ Moreover, considerable resources have been committed to support national and regional investment plans by the European Union, also considering the impact of the Great Recession and the Sovereign debt crisis, in order to improve the innovation performances among EU regions (Archibugi and Filippetti 2011). However, there is no lack of further challenges. Besides globalisation, SMEs face increasing digitalisation, rising energy and commodity prices and an ageing population. Only through new solutions and the necessary investments will we be able to achieve the major breakthroughs required to master these challenges.

The rest of the paper is structured as follows. In Section 2 we analyse the importance of SMEs in the European and Italian economies.

microeconomics (similar to the human spine, which is the nerve center of the body). The economy of a country grows steadily and sustainably as SMEs continually develop.

2 The current EU strategy for 2020 is based on a knowledge based economy, where success will ensure a competitive and dynamic economy sustained in more and better jobs and in a higher level of social cohesion. In this framework, SMEs perform an important role for the sustainable future prosperity of the EU. 
In Section 3 we look at the measurement framework of the European Innovation Scoreboard and focalize our attention on the Italian case. In Section 4 we describe our main lines of research on these topics and finally, Section 5 concludes.

\section{The Role of SMEs in the ItALiAn ECONOMY}

Small and medium-sized enterprises represent a wide business base in every country and play a significant role in the economic development of a country (Bacon and Hoque, 2005). They are considered the backbone of the European economy due to their ability to produce sustainable development through innovation (Konsti-Laakso et al., 2012; Foreman- Peck, 2013), workplaces, and richness for the land they are placed in. At the end of 2016 in Europe, small and medium-sized enterprises accounted for $99 \%$ of firms in the whole EU, providing about $67 \%$ of all jobs in the EU (ec.europa.eu). In the EU, SMEs are around 23 million and provide about 75 million jobs (representing two out of every three private jobs) being responsible for the majority of new jobs created (around 85\%); they represent around 99,7\% of all EU companies; contribute around $50 \%$ of EU exports, contribute to more than half of the total added value created by businesses.

SMEs represent the locomotive of the industrial system also in Italy, not only in terms of industrial structure, but also in terms of their dynamic response to economic downturns. They greatly contribute to economic growth and prosperity, mostly because of their capacity of entrepreneurship, innovation and flexibility in a changing business environment that makes this kind of companies crucial for Europe's competitiveness in a global environment.

In Italy, the fragmentation of the production system is greater than in all the other major advanced economies. In terms of value added and employment, companies with less than 250 employees represent, respectively, about 70 and 80 percent of the total, more than 10 percentage points higher than the average of the European Union countries. In particular, what makes the difference is the strong presence of micro-enterprises, with less than 10 employees. In terms of the number of SMEs, Italy has the largest SME sector in the EU: more than 4.400 million of SMEs - almost twice as much as Germany (2.066 million) - that together guarantee the employment of about $80 \%$ of the 17 million employees in 
the Industry and Services sectors. The vast majority of Italy's SMEs (94.6\% of the total) are micro-firms (less than 10 employees), they are spread in all sectors and their percentage is above the EU average $(92.2 \%)$. Thus, micro and small-medium enterprises have a tremendous economic value in Italy, as well infact as all over the world. They have, furthermore, an extraordinary cultural value since these small economic activities give concrete form to the principles and values of the so called "spirit of entrepreneurship", the latter being intended as a corporate culture characterized by a responsible risk taking capacity, i.e. the talent of accepting the risks intrinsic to entrepreneurial activities while bearing at the same time full responsibility towards all firm's participants. In sum, when considering this peculiar corporate talent, entrepreneurship, freedom and responsibility are three indivisible concepts that should always go hand in hand. Entrepreneurship needs freedom but true entrepreneurship cannot exist without responsibility.

Small economic activities have also another important element which makes them particularly suited to grow as a community of persons. According to the Compendium of the Social Doctrine of the Church:

"Work in small and medium-sized businesses, the work of artisans and independent work can represent an occasion to make the actual work experience more buman, both in terms of the possibility of establishing positive personal relationships in smaller-sized communities and in terms of the opportunities for greater initiative and industriousness. In these sectors, however, there are more than just a few cases of unjust treatment, of poorly paid and, above all, uncertain work" (Compendium of the SDC, n. 315).

In other terms, with respect to big firms or great conglomerates small enterprises are more favorably placed to become close to what should be a firm:

"In fact, the purpose of a business firm is not simply to make a profit, but is to be found in its very existence as a community of persons who in various ways are endeavouring to satisfy their basic needs, and who form a particular group at the service of the whole of society" (Centesimus Annus, n. 35).

This Italian peculiarity has quite old roots and has been accentuated since the Seventies, when the average size of companies has also decreased in other European countries. Until the 1970's, the industrial system in Italy, like in other industrialised economies, experienced the 
managerial capitalism era, characterised by large firms making investments and introducing new technological and organisational innovations. In Italy, however, due to some specific issues, such as the small size of domestic capital and consumption markets, this industrialisation process was carried out through a massive public sector engagement. Progressively, the domestic and international changes in demands and markets as well as the decrease in investments led many Italian large firms to become obsolete with respect to international competitors. Meanwhile, the need for flexibility and customisation to overcome mass production and differentiation fostered the rise of SMEs. These were often organised in industrial districts, i.e. territorial areas characterised by a huge density of small enterprises highly specialised in a specific productive sector and/or process. Thanks to their success on international markets based on the high quality products, which were often the result of noncodified innovation, these highly-specialised industrial districts substantially contributed to strengthening the Italian industrial structure. In the 1990's, the lack of both investments and appropriate public policies supporting technological innovation put this industrial model under severe strain. Nonetheless, the final result was an uncoordinated management of structural changes rather than the whole decline of the Italian industry or the breaking up of its SMEs, which proved to be extremely resilient, especially with regards to their export performance.

Thus, the Italian industrial system should not be assessed according to its firm size distribution, which has proved to be contingent on everchanging economic factors as in other industrialised economies, but rather according to those factors that might either foster or hamper its success. In particular, the analysis should focus on three specific items: investments (including $\mathrm{R} \& \mathrm{D}$ ), innovation and internationalisation, all of them being interconnected indices of dynamism. Profound differences in evaluating this configuration of the production system remain and are still at the core of the economic debate. On the one hand, the high proportion of small and medium-sized enterprises would be nothing else than the outcome of the arrest and retreat of the great process of modernization of the country, whose standard engines are large public and private companies. On the other hand, a large part of the economic literature has shown that Italian small and medium-sized enterprises, especially manufacturing companies that have been able to exploit agglomeration economies in the bright activity of industrial districts, have themselves been the actors of a success story that has combined growth and innovation for a long time. 
The reasons supporting one or the other thesis have lost or gained strength alternately over the last few decades. Technical progress, the evolution of society and the development of the world economy keep shifting the balance between the forces that determine the configuration of the production system. Simplifying, economies of scale and transaction costs push the company towards the great dimension, while organizational diseconomies or localized external economies, i.e. agglomeration economies, tend to reduce company size.

\section{MEASURES OF INNNOVATION: THE EIS FRAMEWORK}

Innovation is not just technological innovation. On the one hand, there are many forms of innovation, e.g. improvements of the existing situation, changes in the way of producing and so on. On the other hand, the ability to innovate depends on a number of parameters: the industrial economic context in which companies find themselves operating, the system of tangible and intangible infrastructures, the support system for business services are just examples. It is very difficult to define which are the optimal conditions for innovation. Certainly, the theme of innovation is crucial both for economic and social issues. For these reasons it is necessary to provide a measure of this phenomenon.

The European Innovation Scoreboard 3 (EIS) provides a comparative analysis of innovation performance in EU countries, other European countries, and regional neighbours. It assesses relative strengths and weaknesses of national innovation systems and helps Member States assess areas in which they need to concentrate their efforts in order to boost their innovation performance. The EIS distinguishes between three main types of indicators - Enablers, Firm activities, and Outputs - and eight innovation dimensions, capturing in total 25 indicators. The measurement framework is presented in Fig. 1. The Enablers capture the main drivers of innovation performance external to the firm and differentiate between three innovation dimensions, ${ }^{4}$ i.e. the Human Resources, the Openess and the Finance and Support system. Firm activities capture the

3 See Hollanders et al. (2016) for details.

4 The Human resources dimension includes three indicators and measures the availability of a high-skilled and educated workforce. Human resources captures New 
innovation efforts at the level of the firm and differentiate between three innovation dimensions, ${ }^{5}$ i.e. Firm investments, Linkages \& Entrepreneurship and the Intellectual Assets. Outputs capture the effects of firms' innovation activities and differentiate between two innovation dimensions, ${ }^{6}$ i.e. Innovators and the Economic effects of innovations.

Innovation performance is then measured using a composite indicator - the Summary Innovation Index (SII) - which summarizes the performance of a range of different indicators. Based on their average innovation performance as calculated by the Summary Innovation Index, Europe's regions are grouped into four innovation performance groups (Fig. 2). The first group of Innovation Leaders includes regions with a performance that stands more than $20 \%$ above the EU average (in particular Denmark Finland, Germany, the Netherlands, and Sweden, whose innovation performance is well above that of the EU average). The second group of Strong Innovators includes regions with performance between $90 \%$ and $120 \%$ of the EU average (in particular Austria, Belgium, France, Ireland, Luxembourg, Slovenia, and the UK with innovation performance above or close to that of the EU average). The third group of Moderate

doctorate graduates, Population aged 30-34 with completed tertiary education, and Population aged 20-24 having completed at least upper secondary education. The Open, excellent and attractive research system includes three indicators and measures the international competitiveness of the science base by focusing on International scientific co-publications, most cited publications, and Non-EU doctorate students. The Finance and support includes two indicators and measures the availability of finance for innovation projects by Venture capital investments and the support of governments for research and innovation activities by R\&D expenditures by universities and government research organizations.

5 Firm investments include two indicators of both $R \& D$ and Non-R\&D investments that firms make in order to generate innovations. Linkages \& entrepreneurship includes three indicators measuring innovation capabilities by looking at SMEs that innovate in-house, collaboration efforts between innovating firms, and research collaboration between the private and public sector. Intellectual assets capture different forms of Intellectual Property Rights (IPR) generated in the innovation process, including PCT patent applications, Community trademarks and Community designs.

6 Innovators include three indicators measuring the share of firms that have introduced innovations onto the market or within their organizations, covering both technological and non-technological innovations, and Employment in fast-growing firms in innovative sectors. Economic effects include five indicators and captures the economic impact of innovation in Employment in knowledge-intensive activities, Exports of medium and high tech products, Exports of knowledge-intensive services, Sales due to innovation activities, and License and patent revenues from selling technologies abroad. 
Innovators includes regions with performance between $50 \%$ and $90 \%$ of the EU average (the performance of Croatia, Cyprus, Czech Republic, Estonia, Greece, Hungary, Italy, Latvia, Lithuania, Malta, Poland, Portugal, Slovakia, and Spain is below that of the EU average). The fourth group of Modest Innovators includes regions with performance below $50 \%$ of the EU average (Bulgaria and Romania are Modest Innovators with innovation performance well below that of the EU average).

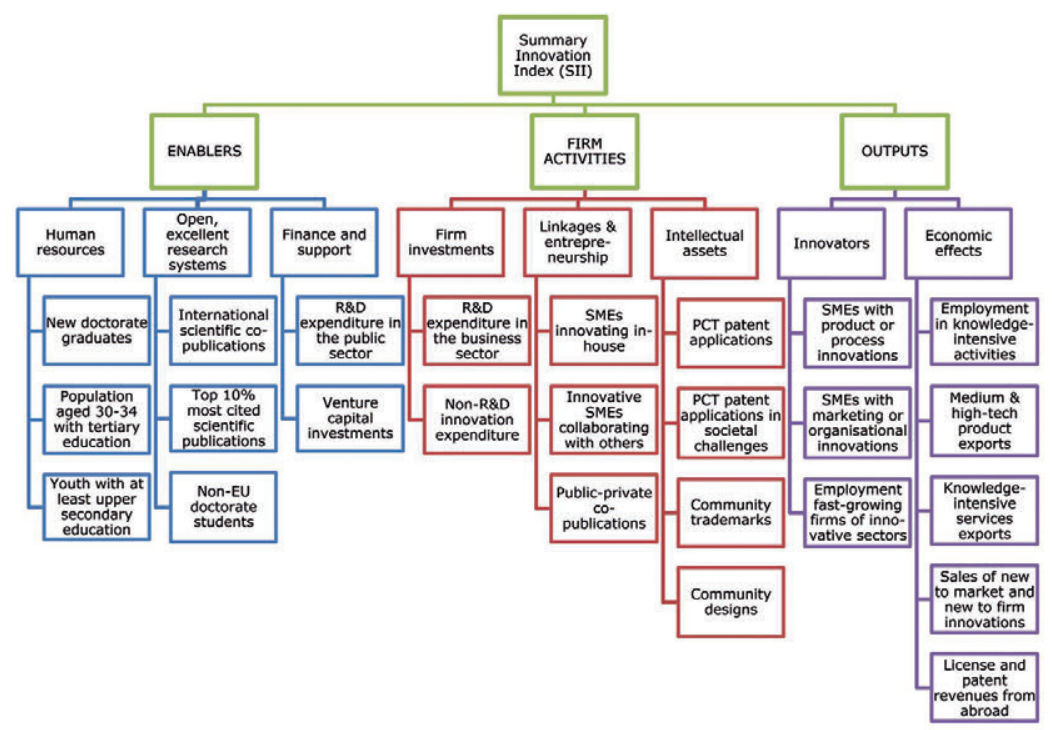

Fig. 1 - Measurement framework of the European Innovation Scoreboard.

Source: European Innovation Scoreboard, 2016.

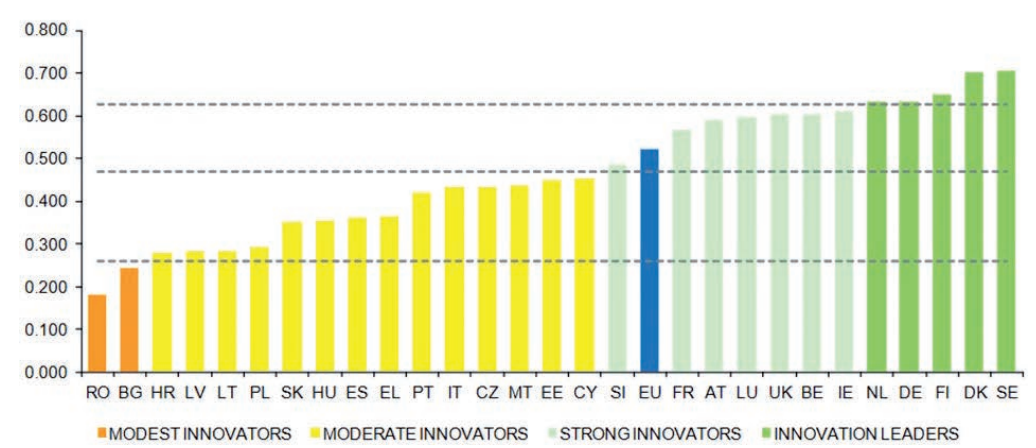

Fig. 2 - EU Member States' innovation performance.

Source: European Innovation Scoreboard, 2016. 
What do the disaggregated data which compose the synthetic indicator say? Let us have a look at the Italian data in the indicators represented in Fig. 3. The first row report the factors that enable innovation (Enablers). The performance in Human Resources reflects (well) the overall classification. The Innovation Leaders are the best performing countries. All Strong Innovators, except Germany, perform above the EU average. Most of the Moderate Innovators perform below the EU average, with only Spain and Estonia performing above this average. Italy, in terms of number of doctorates and graduates produced each year, is below the EU average. The performance in Attractive Research Systems also reflects (well) the overall classification with Innovation Leaders taking the top 5 positions. All Strong Innovators perform above the EU average, except for Germany and Slovenia. Most of the Moderate Innovators perform below the EU average, whereas only Cyprus, Portugal, and Malta perform above the EU average. The Modest Innovators are the worst off, taking the last two positions in the performance ranking. The performance in Finance and Support reflects (well) the overall classification. The Innovation Leaders are the best performing countries behind France, the overall best performing country. Four Strong Innovators perform below the EU average. All Moderate Innovators, e.g. Portugal Spain and Itlay, perform below the EU average.

The second row of Fig. 3 represents Firm activities and captures the innovation efforts at the level of the firm and differentiates between three innovation dimensions. Both Expenditure and Investment in $\mathrm{R} \& \mathrm{D}$ and cooperation between companies are below the EU average.

The economic crisis that started in 2008 has negatively affected business innovation and research and development in all countries especially in Europe. In particular the credit crunch has reduced firm's ability to attract funds and to invest in innovative activities. For these reasons policymakers have tried to increase public funding in order to reduce the structural differences in innovative expenditure between Europe and its main competitors, namely Japan and the United States. In particular, the European Commission has set an $R \& D$ investment objective for the '2020 European Strategy' at 3\% of GDP. Given this goal, support of business $\mathrm{R} \& \mathrm{D}$ and innovative activities remains a major element of innovation policy across European countries. New funding programs and tax incentives for business innovative activities 
have been introduced in a number of countries. The major rationale for such government initiative is that firms may underinvest in innovation under a free market because of the externalities generated by these activities, as well as the information issues associated with these projects (Hall and Lerner, 2010). Hence, government engagement is raised as a mechanism to respond to market failures (Aghion and Howitt, 1990). Looking at Fig. 4, and dividing Public and Private Spending in R\&D we find that the overall Italian spending is around $1.3 \%$ of GDP versus a $2 \%$ EU average. In order to reach the result established by the EU, some targets have been given for each country. As far as Italy, the target is set at $1.5 \%$ of GDP. Performance in Linkages reflects (very) well the overall classification. The Innovation Leaders are represented amongst the top group of countries, together with Strong Innovator countries Belgium, Austria, Germany, and Slovenia. Moderate Innovator Italy shows a performance just below the EU average. The performance in Intellectual assets reflects the overall classification not so well. Three Innovation Leaders and Germany, a Strong Innovator, take up the other top 5 positions, with Denmark ranking second and Sweden third. The United Kingdom, one of the Innovation Leaders, performs below the EU average together with Italy France, Spain and Portugal.
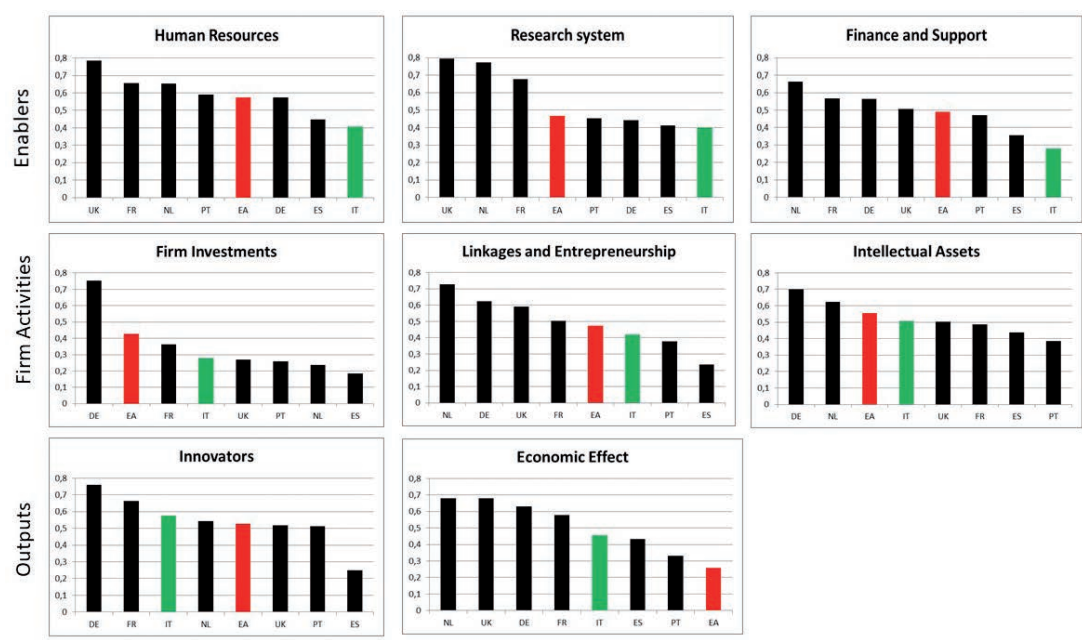

Fig. 3 - Italian Innovation Performance according to disaggregated data. Source: Our elaboration on Innnovation Scoreboard Data, 2016. 


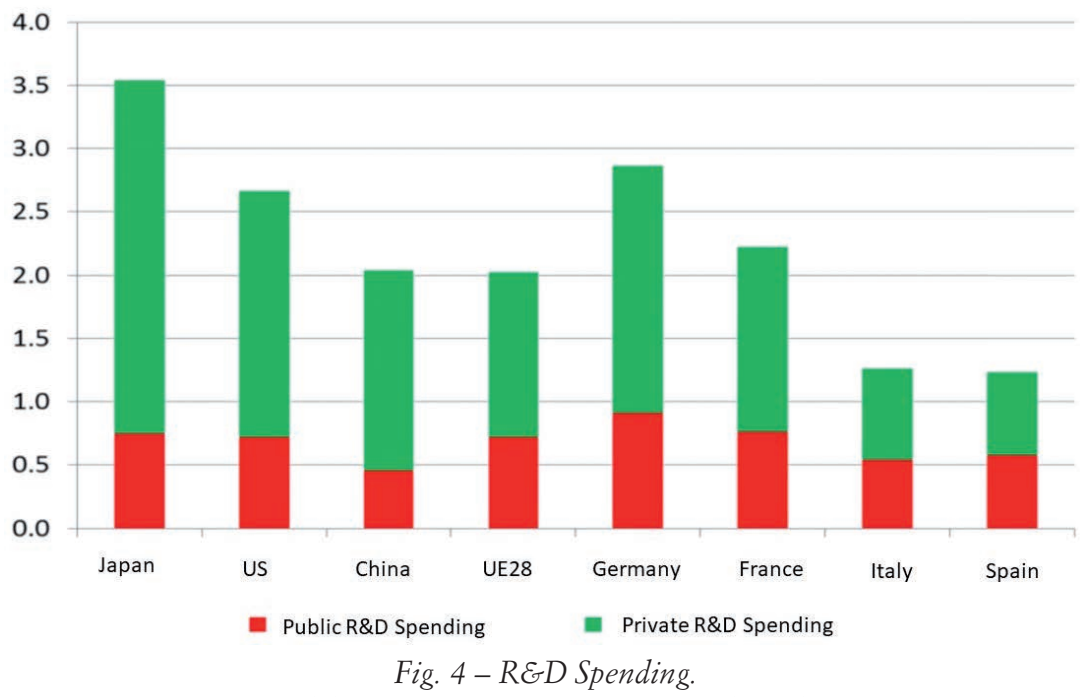

Source: Our elaboration on Innnovation Scoreboard Data, 2016.

The performance in the Innovators dimension reflects to some extent the overall classification. Among Innovation Leaders and Strong Innovators, only the United Kingdom performs below the EU average. Ireland is the overall leader, Belgium ranks second, and Germany third; all three countries are Strong Innovators. There are four Moderate Innovators that perform above the EU average on this indicator: Greece, Portugal, Italy, and Cyprus.

As far as the performance in the Outcome dimension, the two indicators, i.e. innovation and economic performance, are both above the the EU average. Thus, it seems that Italian SMEs have been able to exploit agglomeration economies, due to the fruitful activity of industrial districts, and have been the actors of a success story, by combining product/process innovation with marketing/organizational innovation, which have contributed to growth and innovation (see Fig. 5).

\section{THREE LINES OF RESEARCH}

Given this overall picture of the Italian innovation system, in recent research (see Barbieri L., Bragoli D., Cortelezzi F., Marseguerra G., 2019; Bragoli D., Cortelezzi F., Marseguerra G., 2016; Bragoli D., 
Cortelezzi F., Giannoccolo P., Marseguerra G., 2019; Cortelezzi F., Marseguerra G., Rigon M., Zoia M. G., 2013), we have addressed three specific issues/questions:

a) How are small business R\&D firms' financed? Do decisions depend on the concentration of ownership? What is the composition of companies' ownership? How does the capital structure influence $\mathrm{R} \& \mathrm{D}$ intensity?

b) How much additional R\&D is performed as a result of government support? Does public funding influence innovation behavior? Specifically, do firms improve the management of their R\&D activities? Do firms collaborate more with partners? Are different types of $\mathrm{R} \& \mathrm{D}$ conducted?

c) Is collaboration with Universities beneficial in fostering innovation? Are Universities relevant as a source of information? Is there a potential link between the type of collaboration and the R\&D information source? Is there any impact of the role played by academic collaboration on firm innovation?

SMEs introducing product or process innovations

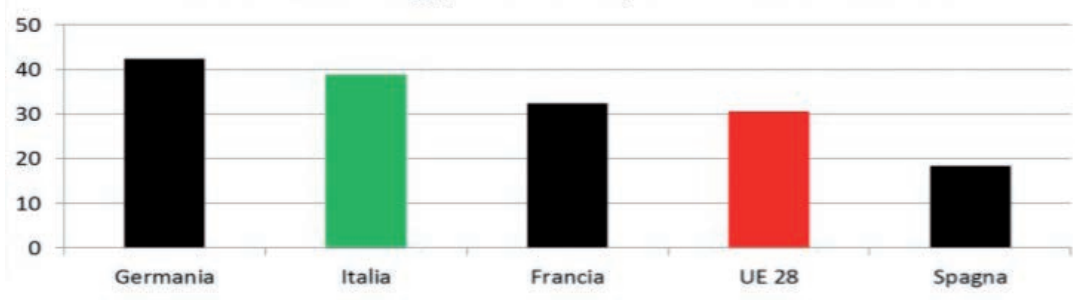

SMEs introducing marketing/organisational innovations

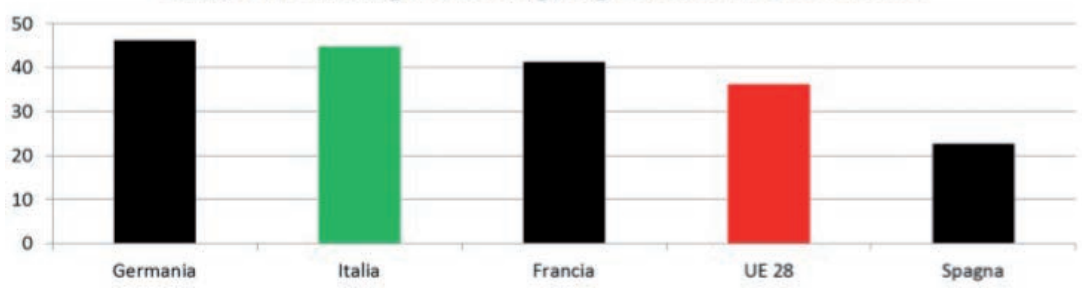

Fig. 5 - Italian technological innovation according to disaggregated data.

Source: Our elaboration on Innnovation Scoreboard Data, 2016.

We base our analysis on a unique company-level integrated dataset, in which we combine the information coming from balance sheet 
data (ASIA) and the Community Innovation Survey (CIS). We use five CIS waves, CIS3 (1998-2000) CIS4 (2002-2004) CIS5 (2004-2006) CIS6 (2006-2008) and CIS7 (2008-2010), to construct a panel dataset of firms in order to exploit both the times series and the cross section information, through the use of an econometric model, by taking into account endogeneity and reverse causality issues and the missing patterns which characterize the CIS.

\subsection{RED and capital structure}

In Bragoli et al. (2016), we explore firm-level data ${ }^{7}$ and investigate two main questions. Do financing choices differ systematically from $R \& D$ intensity? Does a different ownership concentration change this behavior? These two aspects may play a crucial role in firms' ability to advance in the technological frontier.

The first relates to the financing of $R \& D$, a critical input to innovation and growth in modern economies. As Brown, Fazzari, and Petersen (2009) point out, $R \& D$ is particularly interesting not only because of the knowledge spillovers it creates, but also because R\&D may be difficult to finance with external resources, leading to the possible underprovision of $\mathrm{R} \& \mathrm{D}$ investment in the economy. While many papers in this literature (see Hall 2010 for an excellent survey) focus on financing constraints as a source of underinvestment in R\&D (see Bragoli et al. 2019 for a possible theoretical foudation), here we are interested in the nature of more general financing choices made by R\&D intensive firms.

The second relates to firms' governance. ${ }^{8}$ It is often claimed that

7 We use five CIS waves, CIS3 (1998-2000) CIS4 (2002-2004) CIS5 (20042006) CIS6 (2006-2008) and CIS7 (2008-2010), to construct a panel dataset of firms in order to exploit both the times series and the cross section information, through the use of an econometric model, by taking into account endogeneity and reverse causality issues and the missing patterns which characterize the CIS.

8 We proxy ownership concentration with the juridical form of the firm as in Tajoli and Battaggion (2000). We assume that Public Limited Companies (PLC; "società per azioni") are the most capitalized and characterized by a more diluted ownership, on the other hand Private Limited Companies (LTD; "società a responsabilità limitata") represent a more concentrated ownership. The juridical form of the firm is an imperfect indicator of the ownership structure, but it is the only one available given that ownership information for Italian firms is present only for firms traded on the Italian stock market, which are a very small number and not considered in the sample. 
a diluted ownership, as the one prevalent in the United States for example, is ideal for promoting R\&D because it allows the firms to diversify the risk of the project across a large number of investors (Aghion, Van Reenen, and Zingales 2013), while more concentrated ownerships, such as those typical of some European and East Asian countries might be less prone to technological change (Minetti, Murro, and Paiella 2012). In addition, firms' ownership might be relevant in mitigating or exacerbating the agency costs between firms and investors, influencing the relationship between capital structure and $R \& D$ investment.

We find that in Italy, the financial behavior of $R \& D$ intensive firms differs from the financial behavior of firms that invest less in $R \& D$ activities (see Aghion et al. 2013; Wang and Thornhill 2010). In addition, our study points out that the financing choices of firms seem to depend also on the level of ownership concentration. We find an interesting nonlinear (inverted $U$ shaped) relationship with the use of debt financing, as measured by the ratio of total debt to total assets, for public companies. The latter, characterized by a more dispersed ownership, become more reliant on external sources of finance at first preferring debt and then tend to decrease leverage as R\&D intensity increases substituting debt with equity. Limited Responsibility firms, on the other hand, defined by a more concentrated ownership, are not characterized by a significant relation between leverage and $R \& D$ intensity.

From a policy perspective, given this outcome, the analysis performed in this paper allows us to conclude that on one side a cultural change regarding family firms together with public incentives are required to stimulate the opening up of the firm to external equity investors, which can provide new capital. At the same time, measures to stimulate the creation of a venture capital market should be encouraged. On the other side, banks play a fundamental role in the financing of R\&D activities. However, only for Private Limited Companies, banking finance works up to a certain threshold of $R \& D$ since high $R \& D$ intensities represent a substantial risk to banks - not only is the likeli-

9 We focus on the Italian market which is characterized by a number of peculiarities compared to other countries. In particular, there is a prevalence of small and medium unlisted firms, with a very high degree of ownership concentration, that finance their $R \& D$ activities mainly through internal funds and rely almost exclusively on debt as an external source of financing as opposed to equity (see Tajoli and Battaggion 2002 for a detailed analysis of the Italian case). 
hood of default relatively high, but also the lack of tangible assets may leave banks with limited resources in trying to recover their loans. For this reason, any intervention that increases the likelihood that (debt) investors will receive the cash flows, to which they are entitled, represents credit enhancement for the recipient company in that it increases its credibility in the eyes of potential investors (lenders).

\subsection{Public Support to Innovation}

The main focus of the academic literature on this topic has been in detecting how much additional $R \& D$ is performed as a result of government support focusing on $R \& D$ input levels (mainly $R \& D$ expenditure), but also on the outcome of the innovation process and more recently analyzing the influence of public funding on innovation behavior (OECD, 2012) trying to answers questions such as 'Did the firm improve the managementof its $R \& D$ activities?', 'Did the firm collaborate more with partners?', 'Were different types of R\&D conducted?'.

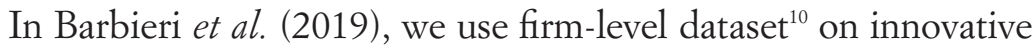
expenditure and public support to innovative activities to focus on their interaction and with the aim of understanding how firms determine their boundaries in terms of innovative strategies. In particular, we consider three different types of $\mathrm{R} \& \mathrm{D}$ strategies: a pure make strategy, i.e the choice of investing in $R \& D$ and other innovative activities only inside the firm, a pure buy strategy, i.e. the choice of investing only in $\mathrm{R} \& \mathrm{D}$ and other innovative activities outside the firm and a composite strategy, which involves both. The Italian case is relevant in the international comparison because Italian firms are usually characterized by a low level of innovation activities (Hall et al., 2009). In Italy, only large firms assign a high priority to formal $R \& D$ activities (internal $R \& D$ ) while SMEs resort mostly to external R\&D, in the form of intermediate and capital goods. In this context, it becomes particularly interesting to

10 Using a unique dataset of Italian companies, which combinesthe information of the Community Innovation Survey - CIS - (referring year 2010) with balance sheet data on companies' characteristics (year 2010, AIDA Bureau van Dijk), we adopt a multi-nomial logit model after controlling for sample selection and endogeneity issues. 
understand what strategy public funding mostly incentives. We measure the impact of public funding on innovation strategy in SMEs, distinguishing in 'in house' innovative activities (make), outsourced innovative activities (buy) or the combination of both (make\&buy).

The important finding from this study is that public funding for innovative expenditure is not only a factor influencing firms' decisions to undertake innovative activities, but it is also a factor that determines the firm's innovative strategic choice. In particular, after receiving public support, firms prefer the composite strategy rather than the single strategies. Interestingly the combined strategy, on the negative side, encloses all the market failures which characterize the single strategies (i.e. information asymmetries towards external borrowers typical of make and high transaction costs and information disclosure typical of buy), on the positive side it incorporates the complementarity between the make and the buy strategies. For example, external R\&D can provide ideas and resources that may help the firm to conduct better in house $\mathrm{R} \& \mathrm{D}$ (absorptive capacity literature). We add another piece of evidence to the political 'evergreen' debate about the necessity to reduce (or not) public subsidies for innovation activity. Although there is no clear consensus about this point, from our analysis we can conclude that public subsidies should be enhanced since they are helpful to stimulate the combined strategy which turns out to be the most promising in terms of technological change and innovation.

\subsection{Cooperation between firms and universities}

In Cortelezzi et al. (2013) we investigate ${ }^{11}$ the role of university linkages and their impact on firms innovation performance in Italy. Italian firms are usually characterized by a low level of innovation activity that is nowadays considered as one of the main reasons to explain the Italian slowdown in the productivity trend of the last fifteen years. The reasons usually addressed to explain this situation refers to the productivity specialization, firms' governance, and especially to the fact

11 We base our analysis on two different surveys carried out by the Bank of Italy: The Bank of Italy's Survey of Industrial and Service Firms (INVIND hereafter) and the Bank of Italy's Business Outloolk Survey of industrial and service firms (SONDTEL). 
that Italian firms are undercapitalized, relying too much on bank credit. Most of these problems have a structural character and cannot be solved in the short run.

Cannari et al. (2007) and De Blasio et al. (2015) study an Italian programme of subsidies for the applied development of innovations; their results indicate that the programme was not effective in stimulating innovative investment. Bronzini and Iachini (2011) and Bronzini and Piselli (2013) further investigate the effectiveness of incentives to foster R\&D and show that small enterprises increased their investments by about the amount of the subsidy they received from the program, whereas for larger firms the subsidies appear to have had no additional effect. Finally, Hall et al. (2010) underline the key role of R\&D on the Italian firms' productivity, although only a third of Italian firms seems to invest in $\mathrm{R} \& \mathrm{D}$ while the remaining part invests in ICT. Thus, the possibility to engage in a collaboration with research oriented partners could be a way to overcome, at least partially, these problems.

Specifically, the novel contribution of the paper is that it disentangles the impact of collaboration in terms of the "importance" of innovative outcome, and whether universities are important information and knowledge sources for the industry. The paper is motivated by the evidence that firms are becoming increasingly aware of the importance of having partners as a source of new knowledge. This awareness stems from the fact that in recent years, rapid technological change, shorter product life cycles and globalization processes, have deeply transformed the current competitive environment. These changes are inducing firms to face stronger competitive pressure which push them to develop new product, to improve productive process or to implement new technologies (see Gomellini, 2013, for a recent survey on innovation and competition). Thus, they need to continually advance knowledge and to innovate. At the same time, entrepreneurs recognize that technological innovations are less and less the outcome of an individual firm's isolated effort (Fisher and Varga, 2002; Drejer and Jorgensen, 2005).

Firms can acquire knowledge and technology from many external partners. These include competing firms, research organizations, government laboratories, industry research associations, and universities. However, the latter are unique in terms of their potential. Universities provide a conduit for the spillover of knowledge from the academic organization, where knowledge is created and transformed, into innovative activity, in order to ultimately enhance the competitiveness of 
firms, industry and the country. As a result of the complementary nature of industry-university relationships, some of these collaborative activities have been instrumental in helping firms to advance knowledge and proper new technologies in many areas, especially in the scientific sector (Metcalfe and Ronnie, 2008). Thus, a deep understanding of the impact of collaboration between firm and university is relevant for the policy implication it might have on the innovation system. It is worth noticing that recently policymakers are putting emphasis on both knowledge transfer and commercialization of academic research. For this reason, in most research projects funded by the European Commission at least one industry partner is required, and this requirement is becoming the norm for government-funded research in many countries.

Results may significantly change according to the definition of innovation and collaboration. In the analysis, innovation is classified according to the degree of novelty, and collaboration has been distinguished according to the effectiveness of the partnership. We show that collaboration with universities is able to increase the probability of a substantial technological innovation. However, the type of partnership plays a relevant role. In other words, we find that the firm-university collaboration is effective in increasing the probability of technological innovation only when there exists a real interaction between partners; it means that "soft contacts" are not sufficient to affect the innovative attitude of firms. Moreover, our findings also contribute to shed some light on the paradox raised by Howells et al. (2012), i.e. it is difficult to conciliate the very low rating that firms assign to universities as a source of information with the impact that universities have on the innovative performance of collaborating firms. We show that universities are privileged sources of information only if the collaboration is "strict".

\section{Concluding Remarks}

Results of our research tend to confirm the analysis based on the European Innovation Scoreboard and offer some policy perspectives.

First, universities are seen as increasingly important players within national and regional innovation systems. Policy-markers' attention is being faced on their economic impact and how this can be manipulated and supported to develop great economic benefits. Our results 
indicate that collaboration with universities is important because it improves the probability of innovative outcomes. Specifically, universities have a more significant impact than any other type of collaborative partner in this respect, since agreements with universities are relevant to improve firms' technological status. More precisely, on the one hand, such agreements are significant in stimulating the innovative performance so that it is possible the development of an entirely new product or production process that allows firms to obtain a patent (i.e. a "drastic innovation"). On the other hand, collaboration with public research is less useful whenever we consider either a progressive product innovation, i.e. a marginal improvement to the components or subsystems of a product, or a process innovation, i.e. the adoption of a new or appreciably improved method of production. Thus, the study concludes that there is a complex interaction between use, impact and value that firms hold with respect to their collaborative relationships with universities within an innovation system.

Then, Public funding for R\&D is not only a factor influencing firms' decisions to undertake $\mathrm{R} \& \mathrm{D}$ activities, but it is also a factor that determines the firm's R\&D strategic choice. In particular firms, after receiving public support, prefer the make and buy strategy rather than the single strategies. Interestingly the combined strategy, on the negative side, encloses all the market failures which characterize the single strategies (i.e. information asymmetries towards external borrowerstypical of make and high transaction costs and information disclosure typical of buy), on the positive side it incorporates the complementarity between the make and the buy strategies. In other words, external R\&D can provide ideas and resources that may help the firm to conduct better in house $R \& D$ (absorptive capacity literature). In this light, the fact that public funding is aimed at supporting the combined strategy turns out to be good news given that government support, correcting for the market failures which characterize the combined strategy, leaves the latter only with its positive aspect, i.e. the positive synergy between internal and external R\&D. Also the Italian ownership of the firm positively impacts on the probability of receiving funding while on the contrary, being part of a group seems to be an obstacle to receiving public support.

Finally, analysing firms' capital structure, public companies become more reliant on external sources of finance at first preferring debt and then tend to decrease leverage as $R \& D$ intensity increases substituting debt with equity. Limited Responsibility firms, on the other 
hand are not characterized by a significant relation between leverage and R\&D intensity. From a policy perspective, the analysis performed allows us to conclude that on one side a cultural change regarding family firms together with public incentives are required to stimulate the opening up of the firm to external equity investors, which can provide new capital. At the same time, measures to stimulate the creation of a venture capital market should be encouraged. On the other side, banks play a fundamental role in the financing of $\mathrm{R} \& \mathrm{D}$ activities. However, only for public companies banking finance works up to a certain threshold of $R \& D$ since high $R \& D$ intensities represent a substantial risk to banks - not only is the likelihood of default relatively high, but also the lack of tangible assets may leave banks with limited resources in trying to recover their loans. For this reason, any intervention that increases the likelihood that (debt) investors will receive the cash flows, to which they are entitled, represents credit enhancement for the recipient company in that it increases its credibility in the eyes of potential investors (lenders)

Without a sound economic theory able to capture the complexity of relations described above, these studies represent a step in a deep understanding process of innovation system. However, some questions still remain without answer. For example, future research should try to investigate i) how it is possible to designe an incentive scheme to improve the collaboration between firm and Univesity; ii) if there exists any additional impact of public support on innovation strategies played by firms; iii) the relationship between information asymmetries and $R \& D$ finance in more detail, for example distinguishing the impact of opaque and transparent R\&D on the financing choice of the firms. The link between the risk levels of a bank portfolio and its probability to finance $R \& D$ also seems a promising future research topic.

\section{REFERENCES}

D. Antonioli, A. Bianchi, M. Mazzanti, S. Montresor, P. Pini, Innovation strategies and economic crisis: evidence from firm-level Italian data, Economia Politica 30, 1 (2013), 33-68.

A. Filippetti, D. Archibugi, Innovation in times of crisis: National Systems of Innovation, structure, and demand, Research Policy 40, 2 (2011), 179-192.

P. Aghion, P. Bolton, An incomplete contracts approach to financial contracting, The Review of Economic Studies 59, (1992), 473-494. 
P. Aghion, J. Van Reenen, L. Zingales, Innovation and institutional ownership, American Economic Review 103, 1 (2013), 277-304.

N. Bacon, K. Hoque, HRM in the SME sector: Valuable Employees and Coercive Networks, The International Journal of Human Resource Management, 16, 11 (2005), 1976-1999.

L. Barbieri, D. Bragoli, F. Cortelezzi, G. Marseguerra, Public funding and innovation strategies. Evidence from Italian SMEs, International Journal of the Economics of Business, (2019) online first.

D. Bragoli, F. Cortelezzi, G. Marseguerra, RED and capital structure: evidence from Italian microdata, Industry and Innovation 23 (2016), 223-242.

D. Bragoli, F. Cortelezzi, P. Giannoccolo, G. Marseguerra, RED Investment timing, default and capital structure, Review of Quantitative Finance and Accounting, (2019) Online first.

R. Bronzini, E. Iachini, Are incentives for RED effective? Evidence from a regression discontinuity approach, American Economic Journal: Economic Policy 6, 4 (2014), 100-134

M. Bugamelli, L. Cannari, F. Lotti, S. Magri, The innovation gap of Italy's production system: roots and possible solutions, Bank of Italy Occasional Paper No. 121, (2012).

J.R. Brown, S.M. Fazzari, B.C. Petersen, Financing innovation and growth: cash flow, external equity, and the 1990s RED boom, The Journal of Finance 64 (2009), 151-185.

L. Cannari, L. D'Aurizio, G. De Blasio, The effectiveness of investment subsidies: evidence from survey data, Rivista Italiana degli Economisti 3 (2007), 329-346.

F. Cortelezzi, G. Marseguerra, M. Rigon, M.G. Zoia, Is collaboration with universities really beneficial for firms? Evidence from Italy, Quaderni del Dipartimento di Discipline matematiche, finanza matematica ed econometria, Università Cattolica del Sacro Cuore 13/6, (2013).

G. De Blasio, D. Fantino, G. Pellegrini, Evaluating the impact of innovation incentives: evidence from an unexpected shortage of funds, Industrial and Corporate Change 24, 6 (2015), 1285-1314.

I. Drejer, B.H. Jørgensen, The dynamic creation of knowledge: analyzing public-private collaborations, Technovation 25 (1), (2005) 83-94.

ECB, Survey on the access to finance of Small and Medium-sized Enterprises in the Euro Area, ECB (2009).

M. Fischer, A. Varga, Technological innovation and inter-firm cooperation: an exploration analysis using data from manufacturing firms in the metropolitan region of Vienna, Technological Managment, 24 (2002), 724-742.

J. Foreman-Peck, Effectiveness and efficiency of SME innovation policy, Small Business Economics, 81, 1 (2013).

M. Gomellini, Innovation and competition: a survey, Bank of Italy (2013) mimeo.

B.H. Hall, The financing of Research and Development, Oxford Review of Economic Policy 18 (2002), 35-51.

B.H Hall., F. Lotti, J. Mairesse, Innovation and productivity in SMEs: empirical evidence for Italy, Small Business Economics, 33 (2009), 13-33. 
B.H. Hall, J. Lerner, The financing of RED and innovation, Handbook of the Economics of Innovation 1 (2010), 609-639.

H. Hollanders, N. Es-Sadki, M. Kanerva, European Innovation Scoreboard. European Commission (2016).

J. Howells, R. Ramlogan, and S.L. Cheng, Innovation and university collaboration: paradox and complexity within the knowledge economy, Cambridge Journal of Economics, 36 (2012), 703-721.

S. Konsti-Laasko, T. Pihkala, S. Kraus, Facilitating SME Innovation Capability through Business Networking. Creativity and Innovation Management, 21, No. 1, (2012), 93-105.

S. Metcalfe, R, Ronald, Innovation systems and the competitive process in developing economies, The Quarterly Review of Economics and Finance, 48, 2 (2008), 433446.

R. Minetti, P. Murro, M. Paiella, Ownership structure, governance, and innovation: evidence from Italy, Government of the Italian Republic (Italy), Ministry of Economy and Finance, Department of the Treasury Working Paper No. 10, (2012).

OECD, OECD Science, Technology and Industry Outlook, OECD 2012.

L. Tajoli, M. Battaggion, Ownership Structure, Innovation Process and Competitive Performance: The Case of Italy, KITeS, Centre for Knowledge, Internationalization and Technology Studies, (2002), Università Bocconi, Milano, Italy.

T. Wang, S. Thornhill, RED investment and financing choices: a comprehensive perspective, Research Policy, 39 (2010), 1148-1159. 
